\title{
Cognitive Auditory Evoked Potential in children with speech sound disorders: analysis of different verbal stimuli
}

Universidade Federal de Santa Maria, Departamento de Fonoaudiologia, Santa Maria, Rio Grande do Sul, Brasil.

Conflict of interests: Nonexistent

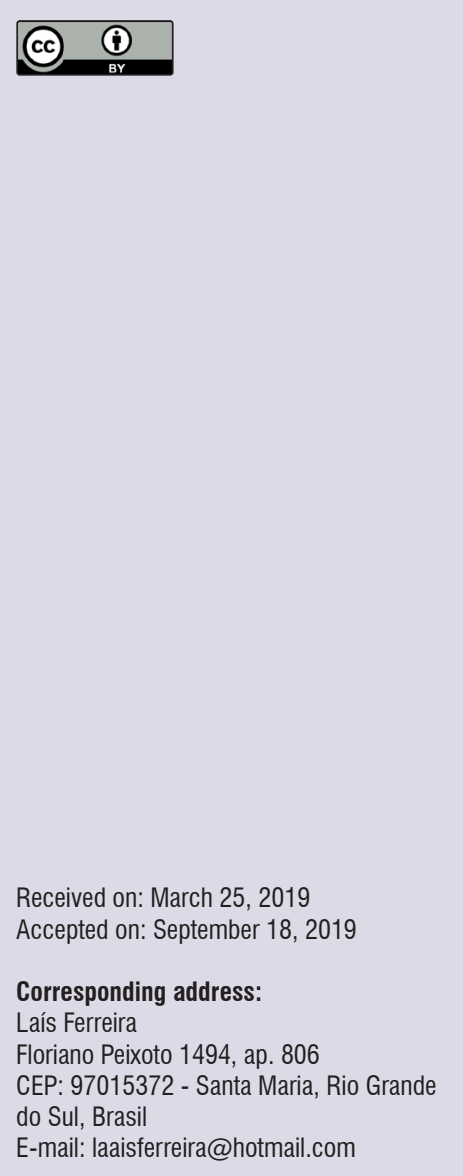

\author{
Laís Ferreira ${ }^{1}$ \\ https://orcid.org/0000-0002-3244-025X \\ Amália El Hatal de Souza ${ }^{1}$ \\ https://orcid.org/0000-0002-5498-2316 \\ Simone Nicolini de Simoni ${ }^{1}$ \\ https://orcid.org/0000-0002-3764-4171 \\ Bianca Bertuol ${ }^{1}$ \\ https://orcid.org/0000-0002-9137-3958 \\ Marileda Barichello Gubiani ${ }^{1}$ \\ https://orcid.org/0000-0003-0692-6480 \\ Márcia Keske-Soares ${ }^{1}$ \\ https://orcid.org/0000-0002-5678-8429 \\ Eliara Pinto Vieira Biaggio ${ }^{1}$ \\ https://orcid.org/0000-0003-2989-5787
}

\section{ABSTRACT}

Objective: to analyze the influence of different combinations of verbal stimuli on the responses of the cognitive auditory evoked potential of children with speech sound disorders and to compare the P300 responses, considering the combinations of stimuli in the different severity of speech sound disorders.

Methods: nineteen children in the mean age of 6.75 years old, of both sexes, diagnosed with speech sound disorder, participated in the study. All participants were submitted to the cognitive auditory evoked potential - P300 test, performed with two combinations of verbal stimuli (BA/DI and BA/GA). For statistical analysis it was used the Student T-test.

Results: a statistically significant difference was observed for the latency values $\left(p=<0.001^{\star}\right)$ and for the amplitude values $\left(p=<0.001^{\star}\right)$ between the two combinations of stimuli. Also, statistically significant difference was observed between the combinations evaluated in the different severity of the speech sound disorder. Conclusion: the combination of stimuli /BA $x / \mathrm{DI} /$ demonstrated lower latency and higher amplitude values in the Cognitive Evoked Potential assessment in children presented with speech sound disorder.

Keywords: Electrophysiology; Auditory Evoked Potentials; Event-Related Potentials, P300; Child; Speech Sound Disorders 


\section{INTRODUCTION}

The cognitive Auditory Evoked Potential (P300), also called event-related potential, provides objective responses of the functionality of the central auditory system. This potential reflects information about the electrophysiological activity at cortical level, involved in attention, discrimination, memory, integration and decision-making ${ }^{1}$. P300 is a positive wave that arises from the discrimination of a rare stimulus within a series of frequent stimuli. This potential involves the accomplishment of a cognitive task; therefore, depends on the subject's conscious response ${ }^{1,2}$. It is known that the P300 component is generated in the region of the auditory cortex ${ }^{1}$.

The cognitive potential has already been studied in different pathologies that present speech-language disorders $^{3-6}$, among them, in children with Speech Sound Disorders (SSD) ${ }^{7-9}$. SSD is characterized by a linguistic disorder in speech, in which the child does not complete the phonological acquisition, i.e., the child present an incomplete phonological system, characterized by phonemes omissions and substitutions, without any association of organic alterations ${ }^{10}$.

It is known that hearing provides the access for speech acquisition and, therefore, it is necessary to understand the functionality of the auditory system, from the detection to the analysis of the sound in the auditory cortex in the child population ${ }^{11}$. In this context, the literature reports that children with SSD may present difficulties in different auditory abilities ${ }^{12-14}$, among them, the ability of auditory discrimination/ phonemic discrimination ${ }^{15,16}$. These difficulties are observed in behavioral and electrophysiological assessments of the central auditory system, such as in the cognitive auditory evoked potential ${ }^{8,9,17}$.

To evaluate P300, different stimuli may be used. A study reports that different stimuli are processed in different ways and generate several cortical responses ${ }^{18-20}$. Among the stimuli used, the verbal stimulus provides a more complex activity and enables the assessment of complex sound processing in the auditory cortex ${ }^{9,19,21}$. Furthermore, once the discrimination of the rare stimulus is essential for the emergence of the cognitive potential, it is emphasized that the degree of contrast between the pairs of stimuli used may influence the latency values of $\mathrm{P} 30 \mathrm{O}^{20}$.

Considering the above, it is possible to observe, in the literature that, although there is evidence of studies related to P300, in children with SSD, there is no study investigating the influence of different stimuli combinations, i.e., pairs with different contrasts in children with SSD. Thus, this study aimed to analyze the influence of two combinations of verbal stimuli on the cognitive auditory evoked potential responses of children with SSD and to compare the P300 responses, considering the stimuli combinations and the severity of SSD.

\section{METHODS}

This research consisted of a quantitative crosssectional study, approved by the Research Ethics Committee of the Federal University of Santa Maria (number CAAE 81117517.0.0000.5346 and opinion $2,538,043)$. All the subjects' responsible signed a written informed consent and the children assented to participate in the research. All mandatory recommendations for research with human beings were observed (Resolution No. 466/12).

Children diagnosed with SSD, aged between 5 and 8 years and 11 months of both sexes, participated in the study. All participants came from research projects at a school clinic. The sample was arranged by convenience.

The exclusion criteria were: (1) to present auditory alteration (hearing loss and/or middle ear alteration); (2) to present another type of language alteration, in addition to learning problems reported by the parents and/or guardians; (3) to have evident neurological and/ or emotional alterations; (4) to not be able to perform the research procedure listed for the present study.

The diagnosis of SSD was performed by a Speech Therapist with experience in the area of language and speech. In order to obtain such diagnosis, the subjects were assessed by means of anamnesis, inspection of the external auditory meatus, Pure Tone Audiometry, through the audiometer AD629, from Interacoustics, Imitanciometry, through the AT235 equipment from Interacoustics, Phonological assessment (INFONO)22, Assessment of Phonological Awareness ${ }^{23}$, Phonological Discrimination Test ${ }^{23}$ and Memory test of words and pseudowords ${ }^{23}$.

According to the evaluations, the SSD were generally considered to be children that presented distinct phonological processes, involving plosives, nasals, fricatives and liquid classes, some of them, also presented consonant reduction processes. These characteristics were presented among the children with SSD. 
It is noteworthy that, even after three months of speech therapy with phonological focus, all subjects still presented SSD, but in different levels.

The phonological assessment was performed using the Phonological Assessment Instrument (INFONO) ${ }^{22}$. This assessment allows the analysis of the data of the phonological system and of the phonetic inventory to generate the results regarding the SSD severity. In order to determine the SSD severity, the Percentage of Correct Consonants-Revised (PCC) ${ }^{24}$ was calculated and classified according to the following levels: Mild Disorder corresponds to more than $85 \%$ of correct consonants; Mild-Moderate Disorder between 85\% and 66\%; Moderate-Severe Disorder between 51\% and 65\%; and Severe Disorder below 50\% of correct consonants ${ }^{24}$.

For a better data analysis, the subjects of this research were divided into two groups, according to their PCC value, being the first one the Mild severity group and the second one the Mild-Moderate AND Moderate-Severe severity group, since only two subjects presented PCC value which indicated Moderate-Severe severity, although such value were close to the reference value of Mild-Moderate.

Twenty-four children were collected. Of these, five subjects were excluded because they did not meet the eligibility criteria. Thus, the sample consisted of 19 children in the mean age of 6.75 years, 11 males and eight females who presented SSD and were undergoing speech therapy for three months.

The research procedure to which the sample group was submitted was the Cognitive Auditory Evoked Potential (P300) performed with two combinations of verbal stimuli. For this purpose, the Smart EP module from Intelligent Hearing Systems (IHS) was used, of two channels with insert earphones. Skin cleansing was performed with the Nuprep ${ }^{\circledR}$ abrasive gel and disposable surface electrodes were used. Regarding the position of the electrodes, the ground electrode (Fpz) was positioned on the forehead, the active electrode was positioned in $\mathrm{Cz}$ (cranial vertex) and connected to channels $A$ and $B$ at the positive input of the preamplifier. The reference electrodes were placed at positions M1 (right mastoid) and M2 (left mastoid) and connected to channels $A$ and $B$ at the negative input of the preamplifier, respectively. It should be noted that the impedance was maintained at 3 kohms.
The stimulation was presented binaurally in the intensity of $80 \mathrm{dBnHL}$ with a presentation rate of 1,1 stimuli per second. The analysis window was of 512 ms (milliseconds), filter of 0,1- $100 \mathrm{~Hz}$. There were 300 stimuli, of which 240 were frequent $(80 \%)$ and 60 were rare $(20 \%)$. It were accepted records with a maximum of $10 \%$ of artifacts of the total stimuli presented.

For the cognitive potential recording, two combinations of verbal acoustic stimuli with different contrasts between the pairs were used, being /BA/ x /DI/ and / $\mathrm{BA} / \mathrm{x} / \mathrm{GA} /$. The selection of these combinations was chosen due to the fact that they present distinct acoustic properties (higher and little contrast, respectively) which may influence the auditory discrimination.

By observing Figure $1(A)$, it is possible to verify that the combinations used differ as to their psychoacoustic properties. It is observed that the syllables /BA/ and / $\mathrm{GA} /$ resemble the frequency range of the stimulus, whereas the syllables /BA/ and /DI/ differ.

In Figure $1(\mathrm{~B})$, it is observed that the combination /BA/ x /DI/ presents greater contrast between the phonemes, for the vowels and for the consonants. The consonants differ in the articulatory point, i.e., /b/ can be considered an anterior phoneme, since it is bilabial and /d/ a consonant that is coronal. Also, the vowels differ in position, vowel /a/, considered open and central, and vowel/i/, considered high, closed and anterior. The counterpoint refers to the combination / $\mathrm{BA} / \mathrm{x} / \mathrm{GA} /$ which presents little contrast, since it has the same vowel (/a/ open and central vowel) and differs only in the articulation point of the consonants, being /b/ an anterior bilabial consonant and /g/ a dorsal, posterior consonant.

In the P300 recording, the syllable /BA/ was used as a frequent stimulus and the syllables /DI/ and /GA/ as rare stimuli. It was chosen to use distinct consonants and vowels in order to evaluate whether this difference would influence the auditory discrimination task of the child with SSD, consequently reflecting the latency and amplitude of the P300.

The first combination presented was the contrast / $\mathrm{BA} / \times$ /DI/. Subsequently, the subject was submitted to the verbal contrast /BA/ x /GA/. All stimuli were generated by the equipment used and it is emphasized that the speech stimuli are unnatural synthetic stimuli. 


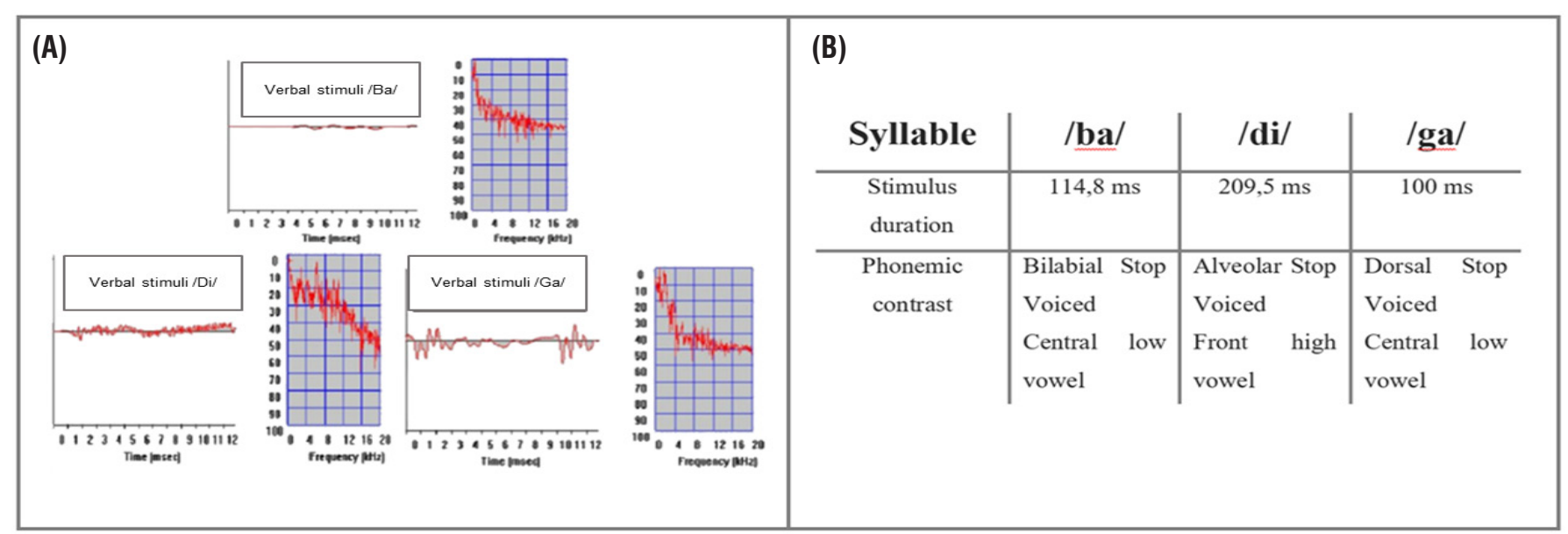

Source figure A: Smart EP module of the Intelligent Hearing Systems (HIS) adapted.

Figure 1. (A) Frequency amplitude spectrum of the syllables used to record the Cognitive Auditory Evoked Potential (P300). (B) Specific characteristics of the syllables used to record the Cognitive Auditory Evoked Potential (P300)

The electrophysiological assessment was performed in a silent room, with the subjects rested, accommodated in an armchair and oriented to maintain attention to rare stimuli (different stimulus), marking the paper every time they have heard them. During the orientations, the children underwent previous training and it was assured that the subject understood the test.

It was sought to keep the children involved and motivated with the test, as well as during the test, to check if the marking was in agreement with the presence of the rare stimulus. When it was observed that the child did not meet the requirements of the test, the same was stopped and restarted. The records considered were the ones in which the child obtained the percentage of 90 to $95 \%$ of the rare stimuli.

Regarding the marking of the P300 wave, the highest peak and amplitude after the P1-N1-P2-N2 complex was considered, around $300 \mathrm{~ms}$ in the pathway, which corresponded to the rare stimuli. The latency and amplitude values of this component were analyzed in milliseconds (ms) and in microvolts $(\mu \mathrm{V})$, respectively. For the marking of the amplitude, guidelines were followed from the manual of the IHS equipment and, thus, it was considered the amplitude from the peak to the next valley.

All potentials were performed in a single session, with intervals and average duration of 60 minutes.

The records were analyzed by two judges trained with theoretical/practical knowledge in electrophysiology of hearing, especially in Long latency auditory evoked potentials (LLAEP). The judges have blindly marked the components of this potential, i.e., they have performed the markings independently on the printed record of the tests. Soon after, the researchers have reproduced such markings in the respective tests in the software of the equipment in question to obtain the values of latency and amplitude with precision.

The data were gathered in a spreadsheet to perform the analysis of the P300 latency and amplitude values. Initially, the Shapiro-Wilk test was used to determine the distribution (normal or non-normal) of the data. Subsequently, a statistical analysis was performed with the T-Student test. A significance level of $0.05(5 \%)$ was defined for this study. Also, the latency and amplitude were analyzed in relation to the variables gender and the severity of the SSD.

\section{RESULTS}

In the comparison of the latency and amplitude values of the P300 component, considering the variable ear (right or left) in the different stimuli combinations, the T-Student test was used, since the data are paired. For latency, no statistically significant difference were observed between the $B A / D I$ combination $(p=0.469)$ and the combination BA/GA $(p=0.828)$. Also, for amplitude, no statistically significant difference were obtained between the BA/DI combination $(p=0.402)$ and BA/GA $(p=0.650)$. This indicates that no statistically difference was observed between the right and left ears in the different stimuli combinations and, thus, the mean was calculated between the ears for future analyzes. 
The variable sex was also analyzed. No statistically significant difference were obtained for the latency values of the $B A / D I$ combination $(p=0.084)$ and the $B A / G A(p=0.568)$. Also, no statistically difference were found for the amplitude values of the BA/DI combination $(p=0.294)$ and the BA/GA combination $(p=0.710)$. These results demonstrate that the P300 values do not present influence of the sex variable.
Based on the analysis between the combinations of stimuli studied, the results of this research indicated statistically significant difference for the analysis of the latency $\left(p=<0.001^{*}\right)$ and amplitude $\left(p=<0.001^{*}\right)$ mean values of the two combinations studied. Lower latency and higher amplitude values were observed for the combination /BA/ x /DI/.

\begin{tabular}{|c|c|c|c|c|c|c|c|}
\hline \multirow[t]{10}{*}{ (A) } & 450 & & \multirow[b]{2}{*}{$T$} & \multirow[t]{2}{*}{ (B) } & 10 & \multicolumn{2}{|c|}{ * } \\
\hline & 400 & & & & en & & \\
\hline & 350 & $T$ & & & 8 & & \\
\hline & 300 & & & & 7 & & $T$ \\
\hline & 250 & & & & 5 & & \\
\hline & 200 & & & & 4 & & \\
\hline & 150 & & & & 3 & & \\
\hline & \multirow{3}{*}{$\begin{array}{r}100 \\
50 \\
0\end{array}$} & & & & \multirow{3}{*}{$\begin{array}{l}2 \\
1 \\
0\end{array}$} & 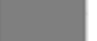 & . \\
\hline & & & & & & & \\
\hline & & $\mathrm{BA} / \mathrm{DI}$ & $\mathrm{BA} / \mathrm{GA}$ & & & $\mathrm{BA} / \mathrm{DI}$ & $\mathrm{BA} / \mathrm{GA}$ \\
\hline \multicolumn{2}{|l|}{ Mean } & 338.4 & 364.8 & \multicolumn{2}{|c|}{ Mean } & 7.93 & 5.88 \\
\hline \multicolumn{2}{|c|}{$\begin{array}{l}\text { Standard Deviation } \\
\text { Minimum }\end{array}$} & 15.62 & 29.68 & \multirow{2}{*}{\multicolumn{2}{|c|}{$\begin{array}{l}\text { Standard Deviation } \\
\text { Minimum }\end{array}$}} & 2.81 & 1.21 \\
\hline \multirow{2}{*}{\multicolumn{2}{|c|}{$\begin{array}{l}\text { Minimum } \\
\text { Maximum }\end{array}$}} & 305 & 306 & & & 3.84 & 3.83 \\
\hline & & 359 & 413 & \multicolumn{2}{|l|}{ Maximum } & 13.41 & 8.09 \\
\hline \multicolumn{2}{|l|}{$\mathrm{N}$} & 19 & 19 & \multicolumn{2}{|l|}{$\mathrm{N}$} & 19 & 19 \\
\hline
\end{tabular}

In images $(A)$ and $(B)$, the asterisk $\left(^{*}\right)$ indicates statistically significant difference, corresponding to the value of $p 0.017$ and $p=0.047$, respectively. Legend: $\mathrm{n}=$ sample number; $\mathrm{ms}=$ milliseconds; $\mu \mathrm{V}=$ microvolts.

Statistical test: T-Student

Figure 2. (A) Comparison of latency mean values, in milliseconds, of two combinations of verbal stimuli used to perform the Cognitive Auditory Evoked Potential $(n=19)$. (B) Comparison of amplitude mean values, in microvolts, of two combinations of verbal stimuli used to perform the Cognitive Auditory Evoked Potential $(n=19)$

The difference between the stimuli combinations studied in the different severities of the SSD (mild, mildmoderate and moderate-severe) was also analyzed.
In this analysis, a statistically significant difference was obtained between the stimulus combinations for children with the same severity of SSD. 
Table 1. Comparison of latency, in milliseconds, and amplitude, in microvolts, of two combinations of verbal stimuli used in the performance of the Cognitive Auditory Evoked Potential, in the different severity levels of speech sound disorders $(n=19)$

\begin{tabular}{|c|c|c|c|c|c|}
\hline \multicolumn{2}{|c|}{ Latency P300 (ms) } & Mean & Standard Deviation & $n$ & $p$ value \\
\hline \multirow{2}{*}{ Mild } & $\mathrm{BA} / \mathrm{DI}$ & 344.3 & 11.74 & 8 & \multirow{2}{*}{$<0.001^{*}$} \\
\hline & $\mathrm{BA} / \mathrm{GA}$ & 377.0 & 33.83 & 8 & \\
\hline \multirow{2}{*}{$\begin{array}{l}\text { Mild-Moderate and } \\
\text { Moderate-Severe }\end{array}$} & $\mathrm{BA} / \mathrm{DI}$ & 334.1 & 17.17 & 11 & \multirow{2}{*}{$<0.001^{*}$} \\
\hline & $\mathrm{BA} / \mathrm{GA}$ & 356.0 & 24.08 & 11 & \\
\hline \multicolumn{2}{|c|}{ Amplitude P300 $(\mu \mathrm{V})$} & Mean & Standard Deviation & $\mathbf{N}$ & $p$ value \\
\hline \multirow{2}{*}{ Mild } & $\mathrm{BA} / \mathrm{DI}$ & 6.85 & 3.20 & 8 & \multirow{2}{*}{$0.01^{*}$} \\
\hline & $\mathrm{BA} / \mathrm{GA}$ & 5.62 & 1,18 & 8 & \\
\hline \multirow{2}{*}{$\begin{array}{l}\text { Mild-Moderate and } \\
\text { Moderate-Severe }\end{array}$} & $\mathrm{BA} / \mathrm{DI}$ & 8.72 & 2.32 & 11 & \\
\hline & $\mathrm{BA} / \mathrm{GA}$ & 6.08 & 1.25 & 11 & $<0.001^{*}$ \\
\hline
\end{tabular}

Legend: Hz: Hertz; n: sample number; $\mu$ V: Microvolts

Statistical test: T- Student

\section{DISCUSSION}

The results of this research showed that there is a statistically significant difference between the P300 latency and amplitude values when stimuli combinations with different contrasts were used in children with SSD. Thus, it is emphasized that the selection of the stimulus used to record this potential may be reflected in the generation time and the magnitude of the neural response.

In the comparison analysis of the ear variable in the combinations of stimuli, it was verified equivalence between the right and left ears for the latency and amplitude values. Another study also observed this equivalence in the auditory pathway of the pediatric population ${ }^{18,25,26}$.

It is worth noting that this study did not present a control group, since the literature already presents reference values for the Cognitive Potential (P300) in children with $S_{S D}^{8,9}$. These authors found that this population presents higher mean values of latency compared to the typical children population ${ }^{8,9}$. In addition, the aim of this study was not to generate P300 reference values in the population with SSD, but to understand the behavior of the two combinations of verbal stimuli in this population. The mean values of latency observed for the two stimulus combinations presented in this study are similar to those described in the literature for this population ${ }^{8,9}$.

As a result of the comparison between the two stimuli combination (Figure 2), it was possible to observe better responses when the /BA/ x /DI/ combination was used, i.e., in the P300 record, the /BA/ $\mathrm{x} /$ $\mathrm{DI} /$ obtained lower latencies and higher amplitudes values. In this study, it was observed that different stimuli generate different cortical responses ${ }^{18-20}$, since they present different physical and temporal characteristics. Thus, it is noted that the selection of stimulus may influence the electrophysiological responses of the cognitive auditory evoked potential. Similar findings were observed in national studies in children with typical development. These authors report that the choice of stimulus has a significant influence on longlatency auditory evoked potential responses ${ }^{20}$, and their analyzes for both consonant and vowel contrasts ${ }^{18}$.

Analyzing Figure $1(A)$, which shows the spectrum of frequencies and amplitude of the syllables used to record the P300, it is possible to observe a difference in the psychoacoustic properties between the syllables studied. In this context, the present study demonstrates that such psychoacoustic difference influences the auditory discrimination of children with SSD. Also, regarding the psychoacoustic differences, it is verified that the amplitude of the frequency between the syllables /BA/ and /DI/, where in addition to the consonants, the vowels also differ, presenting higher spectral contrast, thus enabling a better auditory discrimination by the subject ${ }^{27}$. The decrease in the latency values for the /BA/ x /DI/ combination when compared to another verbal stimuli was also evidenced in a study with similar methodology, but in the adult population ${ }^{28}$.

As for the phonology of the combinations studied, it is verified that for the /BA/ $\times / \mathrm{DI} /$ combination, the two consonants present the distinctive feature trait [+ voice], but they differ in the articulatory point (bilabial $x$ coronal), and also in the central and high vowels, which is more easily perceived by the child. However, in the 
combination $/ \mathrm{BA} / \times / \mathrm{GA} /$, the $/ \mathrm{g} /$ sound also differs in the articulatory point when compared to the others. The phoneme $/ \mathrm{g} /$ is dorsal, for this reason, it is more difficult to perceive such combination. The plosive phonemes are characterized by a range of obstruction of the articulators followed by a sudden release of the air current, which may favor the child's auditory perception ${ }^{27}$.

In addition to facilitate perception, the differences in the psychoacoustic properties, articulatory points of the consonants (bilabial $x$ coronal) and vowels (central $x$ high) of the combination $/ \mathrm{BA} / x / \mathrm{DI} /$ requires attention. That is, to perceive such difference, the child is required to pay attention, which is necessary for a good performance in the auditory discrimination task ${ }^{29}$.

Regarding the analysis of the two combinations of stimuli in the SSD severity (Table 1), a statistically significant difference was observed between the combinations for children with the same severity of SSD. Reinforcing the data observed in figure 2, for this analysis, the /BA/ x /DI/ combination also showed lower latency and higher amplitude, when compared to the combination /BA/ x/GA/ in children with the same level of severity. These results infer that regardless of the SSD severity, the combination /BA/ x /DI/ can be a facilitator for the P300 assessment.

The results obtained in this study demonstrate that the P300 electrophysiological responses are related to physical and temporal characteristics of the stimuli. In addition, the combination of stimulus /BA/ $x / \mathrm{DI} /$ facilitates the task of auditory discrimination for children with SSD.

\section{CONCLUSION}

The electrophysiological responses of the Cognitive Auditory Evoked Potential are influenced by the psychoacoustic properties of the stimulus. The stimuli combination /BA/ x /DI/ presented lower latency and higher amplitude values in the P300 assessment in children with speech sound disorders. Thus, it is emphasized that the selection of the stimulus for the recording of this potential may reflect in the generation time and the magnitude of the neural response.

\section{REFERENCES}

1. McPherson DL. Late potentials of the auditory system. San Diego: Publishing Group; 1996.

2. Reis AC, Frizzo CF. Potencial evocado auditivo cognitivo. In: Boéchat EM, Menezes PL, Couto CM, Frizzo AC, Scharlach RC, Anastacio AR (eds).
Tratado de Audiologia. Rio de Janeiro: Guanabara Koogan; 2015. p.140-50

3. Prestes R, Andrade AN, Santos RBF, Maragoni AT, Schiefer AM, Gil D. Temporal processing and long-latency auditory evoked potential in stutterers. Braz J Otorhinolaryngol. 2017;83(2):142-6.

4. Cañete OM, Purdy SC, Neeff M, Brown CRS, Thorne PR. Cortical auditory evoked potential (CAEP) and behavioural measures of auditory function in a child with a single-sided deafness. Cochlear Implants Int. 2017;18(6):1-12.

5. Papagiannopoulou EA, Lagopoulos J. P300 eventrelated potentials in children with dyslexia. Ann Dyslexia. 2017;67(1):99-108.

6. Wang S, Yang C, Liu Y, Shao Z, Jackson T. Early and late stage processing abnormalities in autism spectrum disorders: an ERP study. PLoS One. 2017;12(5): e0178542

7. Advíncula KP, Griz SMS, Frizzo ACF, Pessoa ACRG, Leite-Barros PMA, Gurgel E. Potenciais evocados auditivos de longa latência em crianças com desvio fonológico. Distúrb. Comun. 2008;20(2):171-81.

8. Leite RA, Wertzner HF, Matas CG. Long latency auditory evoked potentials in children with phonological disorder. Pró-Fono $\mathrm{R}$ Atual. 2010;22(4):561-6.

9. Leite RA, Wertzner HF, Gonçalves IC, Magliaro FCL, Matas CG. Auditory evoked potentials: predicting speech therapy outcomes in children with phonological disorders. CLINICS. 2014;69(3):212-8.

10. Ceron MI, Gubiani MB, Oliveira CRD, Gubiani MB, Keske-Soares M. Prevalence of phonological disorders and phonological processes in typical and atypical phonological development. CoDAS. 2017;29(3):1-9.

11. Samelli AG, Rondon-Melo S, Rabelo CM, MoliniAvejonas DR. Association between language and hearing disorders-risk identification. Clinics. 2017;72(4):213-7.

12. Melo Â, Mezzomo CL, Garcia MV, Biaggio EPV. Effects of computerized auditory training in children with auditory processing disorder and typical and atypical phonological system. Audiol. Commun. Res. 2016;21:e1683.

13. Murphy CFB, Pagan-Neves LO, Wertzner HF, Schochat E. Children with speech sound disorder: comparing a non-linguistic auditory approach with a phonological intervention approach to improve phonological skills. Front Psychol. 2015;6:64. 
14. Vilela N, Barrozo TF, Pagan-Neves LO, Sanches SGG, Wertzner HF, Carvallo RMM. The influence of (central) auditory processing disorder on the severity of speech-sound disorders in children. Clinics. 2016;71(2):62-8.

15. Brancalioni AR, Bertagnolli APC, Bonini JB, Gubiani MB, Keske-Soares M. The relation between auditory discrimination and phonological disorder. J Soc Bras Fonoaudiol. 2012;24(2):157-61.

16. Freitas CRD, Mezzomo CL, Vidor DCGM. Phonemic discrimination and the relationship with other linguistic levels in children with typical phonological development and phonological disorder. CoDAS. 2015;27(3):236-41.

17. Melo ÂD, Mezzomo CL, Garcia MV, Biaggio EPV. Computerized auditory training in students: electrophysiological and subjective analysis of therapeutic effectiveness. Int Arch Otorhinolaryngol. 2018;22(1):23-32.

18. Alvarenga KF, Vicente LC, Lopes RCF, da Silva RA, Banhara MR, Lopes AC et al. The influence of speech stimuli contrast in cortical auditory evoked potentials. Braz $\mathrm{J}$ Otorhinolaryngol. 2013;79(3):336-41.

19. Matas CG, Silva FBL, Carrico B, Leite RA, Magliaro FCL. Long-latency auditory evoked potentials in sound field in normal-hearing children. Audiol Commun Res. 2015;20(4):305-12.

20. Silva LSD, Regaçone SF, Oliveira ACSD, Oliveira LSD, Fernandes FT, Frizzo ACF. Auditory cortical potential: using different types of speech stimuli in children. Audiol Commu Res. 2017;22:e1788.

21. Francelino EG, Reis CFC, Melo T. The use of $P 300$ with speech stimulus for monitoring the auditory training. Distúrb. Comun. 2014;26(1):27-34.

22. Ceron MI, Gubiani MB, Oliveira CRD, KeskeSoares M. Evidence of validity and reliability of a phonological assessment tool. CoDAS. 2018;30:e20170180-e20170180.

23. Seabra AG, Capovilla FC. Prova de Consciência Fonológica por produção oral. In: Seabra AG, Dias NM (eds). Avaliação neuropsicológica cognitiva: linguagem oral. São Paulo: Memnon; 2012. p.116-20.

24. Shriberg LD, Austin D, Lewis BA, McSweeny JL, Wilson DL. The speech disorders classification system (SDCS): extensions and lifespan reference data. J Speech Lang Hear Res. 1997;40(4):723-40.
25. Almeida RP, Matas CG. Long latency auditory evoked potentials in malnourished children. CoDAS. 2013;25(5):407-12.

26. Agostinho-Pesse RS, Alvarenga KF. Late auditory evoked potentials to speech stimuli presented with different transducers in hearing children. Rev. CEFAC. 2014;16(1):13-22.

27. Melo RM, Mota HB, Mezzomo CL, Brasil BC, Lovatto L, Arzeno L. Parâmetros acústicos do contraste de sonoridade das plosivas no desenvolvimento fonológico típico e no desviante. Rev Soc Bras Fonoau. 2012;17(3):304-12.

28. Didoné DD, Oppitz SJ, Silva DD, Gois M, Folgearini JS, Ferreira GC et al. P3 cortical potential: difficulty level for different stimulus. Audiol Commun Res. 2015;20(3):233-8.

29. Orduña I, Liu EH, Church BA, Eddins AC, Mercado E. Evoked-potential changes following discrimination learning involving complex sounds. Clin Neurophysiol. 2012;123(4):711-9. 